\title{
Correction to: Dephosphorization Kinetics between Bloated Metal Droplets and Slag Containing FeO: The Influence of CO Bubbles on the Mass Transfer of Phosphorus in the Metal
}

\author{
KEZHUAN GU, NESLIHAN DOGAN, and KENNETH S. COLEY
}

DOI: $10.1007 / \mathrm{s} 11663-017-1113-7$

(C) The Minerals, Metals \& Materials Society and ASM International 2017

Correction to: Metallurgical and Materials Transactions B DOI 10.1007/s11663-017-1070-1

AN error occurred in the Table VI of this paper. The values used in this paper for diffusivity of phosphorus in the metal phase were incorrectly entered in Table VI. The values should be as listed in the following Table VI.

Table VI. Parameters for Calculating $k_{m}$ of 0.007 wt pet S Bloated Droplets in the Foam

\begin{tabular}{lccc}
\hline Parameter & $1813 \mathrm{~K}\left(1540{ }^{\circ} \mathrm{C}\right)$ & $1853 \mathrm{~K}\left(1580{ }^{\circ} \mathrm{C}\right)$ & $1913 \mathrm{~K}\left(1640{ }^{\circ} \mathrm{C}\right)$ \\
\hline Diffusivity $\times 10^{5}\left(\mathrm{~cm}^{2} / \mathrm{s}\right)^{[37]}$ & 1.86 & 2.14 & 2.62 \\
\hline
\end{tabular}

KEZHUAN GU, NESLIHAN DOGAN, and KENNETH $\mathrm{S}$. COLEY are with the Department of Materials Science and Engineering, McMaster Steel Research Centre, McMaster University, 1280 Main Street West, Hamilton, ON, L8S 4L7, Canada. Contact e-mails: guk3@mcmaster.ca and coleyk@mcmaster.ca

The online version of the original article can be found under doi: 10.1007/s11663-017-1070-1.

Article published online October 31, 2017. 